\title{
In vitro Comparative Quality Assessment of Different Brands of Furosemide Tablets Marketed in Northwest Ethiopia
}

This article was published in the following Dove Press journal:

Drug Design, Development and Therapy

\author{
Simachew Abebe ${ }^{1,2}$ \\ Gebremariam Ketema (D) \\ Haile Kassahun (iD) \\ 'Department of Pharmacy, College of \\ Medicine and Health Sciences, Wollo \\ University, Dessie, Ethiopia; ${ }^{2}$ Chagni \\ Primary Hospital, Chagni, Amhara \\ Region, Ethiopia
}

Background: The use of ineffective and poor quality drugs endangers therapeutic treatment and may lead to treatment failure. For desired therapeutic effect, drugs should contain the appropriate amount of active pharmaceutical ingredient and the required physical characteristics.

Aim: The aim of this study was to evaluate quality as well as physicochemical bioequivalence of different brands of furosemide tablets marketed in Bahir Dar, Northwest Ethiopia.

Methods: Five different brands of furosemide tablets were purchased from community pharmacies in Bahir Dar city, Northwest Ethiopia. The quality control parameters of furosemide tablets were determined by identification, weight variation, disintegration, assay and dissolution tests and the results were compared with USP and BP pharmacopoeial standards. Difference (f1) and similarity (f2) factors were calculated to assess in vitro bioequivalence requirements.

Results: Identification test results revealed that all samples contained the stated active pharmaceutical ingredients. The results of weight variation tests indicated that all samples complied with USP specification limits. The active pharmaceutical ingredients quantitative assay showed that all the brands of furosemide tablets were between the $90 \%$ and $105 \%$ limit of label claim. Similarly, all samples fulfilled disintegration time (i.e., $\leq 30 \mathrm{~min}$ ) and dissolution tolerance limits (i.e., $\mathrm{Q} \geq 80 \%$ at $60 \mathrm{~min}$ ). Hence, none of the samples were found to be counterfeit and/or substandard. Difference factor (f1) values were $<15$ and similarity factor (f2) values were $>50$ for all the tested brands of furosemide tablets.

Conclusion: This study revealed that all the furosemide brands met the quality specification of weight variation, hardness, friability, dissolution, disintegration and assay. The study also indicated similarity in the dissolution profile of the brands of furosemide tablets with the innovator product. Hence, all of these generic brands could be substituted with the innovator product in clinical practice.

Keywords: quality, weight variation, assay, dissolution, identification, furosemide tablets, Northwest Ethiopia

\section{Introduction}

Most patients with hypertension require drug treatment to achieve sustained reduction of blood pressure. There are different groups of anti-hypertensive drugs such as diuretics, calcium-channel blockers, $\beta$-blockers, angiotensin converting enzyme inhibitors and angiotensin II receptor blockers. Of these, calcium channel blockers and diuretics are two of the most important groups used for the treatment of hypertension. ${ }^{1}$
Correspondence: Haile Kassahun Department of Pharmacy, College of Medicine and Health Sciences, Wollo University, Dessie, Ethiopia

Tel +251 910800359

Email Haile.kassahun@wu.edu.et 
Furosemide is a widely prescribed and powerful diuretic drug used in the management of edema and hypertension. ${ }^{2}$ It is also used for acute and chronic heart failure, severe hypertension and edematous conditions. ${ }^{3}$ Furosemide is 4-Chloro2-[(furan-2-ylmethyl) amino]-5-sulfamoylbenzoic acid; it is a white, crystalline powder having the molecular formula $\mathrm{C}_{12} \mathrm{H}_{11}{\mathrm{C} 1 \mathrm{~N}_{2}}_{2} \mathrm{O}_{5} \mathrm{~S}$ and molecular weight $330.7 \mathrm{~g} / \mathrm{mol}^{4}{ }^{4}$

Pharmaceuticals play an important role in improving human health and promoting wellbeing. Safety, efficacy, and quality of drugs must be ascertained to provide a desired pharmacological effect. Pharmaceuticals must fulfill regulatory requirements to meet quality standards. Moreover, to ensure safety and efficacy, the quality of pharmaceutical products must be reliable and reproducible. ${ }^{5-7}$ The quality of pharmaceutical products can be evaluated using in vivo or in vitro tests. ${ }^{8}$

The quality of medicines is a topic of global concern, particularly in many developing countries. ${ }^{9}$ The prevalence of counterfeit drugs in the global market is reaching epidemic proportions with developing countries affected to a greater degree. ${ }^{10}$ Low and middle income countries are especially affected due to inadequate facilities, few trained personnel and weak regulatory systems which fail to ensure the quality of medicines and to carry out regular surveillance for substandard and falsified products. Poor quality medicines can be the result of poor manufacturing practices, counterfeiting, or inappropriate drug storage. There is an increased number of hospital admissions and deaths due to quality defects of drugs..$^{8-10-12}$ The use of ineffective and poor quality drugs endangers therapeutic treatment and may lead to treatment failure. ${ }^{13}$

The circulation of substandard medicines remains a serious problem in resource-limited countries in subSaharan Africa, where most of the drugs available are imported. Medicines sold in these markets are frequently found to have ingredients at concentrations that are too high or too low. ${ }^{14}$ For example, a drug quality study from 10 African countries found that nearly a quarter of generic antihypertensive medicines were of low quality. ${ }^{15}$ Similarly, a study on quality assessment of seven cardiovascular drugs in 10 sub-Saharan countries indicated that $12.5 \%$ of furosemide samples were identified as being poor quality. In Nigeria, a quality check of an antihypertensive medicine (nifedipine) was done on a total of 14 brands; of 102 samples, 78 (76.5\%) were poor quality. ${ }^{16}$

Some studies in Ethiopia have also proved the existence of substandard drugs in the country. A nationwide survey conducted in Ethiopia on the quality of mebendazole, albendazole, and tinidazole medicines found that $45.3 \%$ of the samples did not fulfill pharmacopoeia quality specifications. ${ }^{17}$ Similarly, Solomon Hambisa et al. studied 10 brands of norfloxacin tablets and reported that two brands did not meet the specified USP dissolution requirement. The study also revealed the similarity in the dissolution profile of two brands of norfloxacin tablets $(25 \%)$ with the comparator product. $^{7}$ Abuye et al. indicated that $28.3 \%, 31.7 \%$, and $6.8 \%$ of antimalarial medicines (chloroquine phosphate and quinine sulfate tablets) failed to comply with the pharmacopoeial quality standards for visual inspection, hardness and weight variation tests, respectively. ${ }^{18}$ Seifu et al. found that all batches of albendazole circulating in the market in Addis Ababa did not fulfill either physical or chemical quality standards. ${ }^{19}$ These findings revealed that the Ethiopian health system could be endangered with poor quality medicines. Hence, there is the need for continuous assessment of the pharmaceutical quality of essential drugs circulating in the market to ensure the quality of these medicines. This is of particular importance with therapeutics used in the treatment of chronic diseases for which daily, long-term therapy is required. ${ }^{20}$ Moreover, Ethiopia is one of the sub-Saharan African countries where the poor regulation of medicines and lack of a bioequivalence testing center pose difficulties in guaranteeing effective generic drug substitution. ${ }^{21}$ Since furosemide tablets are widely prescribed drugs, lifesaving and used lifelong, regular post-market quality control assessment is necessary. Hence, the present study was conducted to assess the quality as well as physicochemical equivalence of different brands of furosemide tablets marketed in Bahirdar, Northwest Ethiopia.

\section{Materials and Methods \\ Materials \\ Chemicals, Reagents and Solvents}

Furosemide reference standard was a gift from the Ethiopian Food and Drug Administration Authority (EFDA). All reagents and solvents used for this experiment were: glacial acetic acid (Loba Chemie Pvt. Ltd, India), HPLC grade acetonitrile (Sisco Research Laboratories Pvt. Ltd, India), sodium hydroxide pellets (Neo Lab Life Science Co., India), tetrahydrofuran (Loba Chemie Pvt. Ltd, India), potassium dihydrogen phosphate (Guangdong Guanghua Sci-Tech Co. Ltd, China) and orthophosphoric acid (Loba Chemie Laboratory reagents and fine chemicals, India). 


\section{Instruments and Apparatus}

The following instruments were used for in vitro quality control assessment of furosemide tablets. High performance liquid chromatography $\left(4.6 \mathrm{~mm} \times 25 \mathrm{~cm} \mathrm{C}_{18}\right.$ column, UVVis detector, Thermo Fisher, USA), single beam UV-visible spectrophotometer (Evolution 201, Thermo Fisher, USA), analytical balance (MS205DU, Mettler Toledo, USA), PH meter (FE-28 standard, Mettler Toledo, USA), hardness tester (YD-20KZ, Tianda-Tianfa, China), friability tester (FT2000SE, Tianda-Tianfa, China), disintegration time test apparatus (ZB-1E, Tianda-Tianfa, China), dissolution test apparatus II (ZRS-8G, Tianjin instrument factory, China) and shaking incubator (THZ-300, Shanghai-Yiheng, China) were used.

\section{Sampled Drug Products}

Five different brands of furosemide $40 \mathrm{mg}$ tablets were purchased from community pharmacies in Bahir Dar City, Northwest Ethiopia. Each brand of furosemide tablets was randomly coded from $F_{1}$ to F5. All brands of furosemide tablets were purchased with their original packaging and were within their expiration dates (Table 1).

\section{Methods}

\section{Study Area and Study Design}

The study was conducted in Bahir Dar city, Northwest Ethiopia. A laboratory based cross-sectional study was conducted from February 2019 to June 2020 to assess quality as well as the physicochemical bioequivalence of different brands of furosemide $40 \mathrm{mg}$ tablets marketed in the community pharmacies of Bahir Dar City, Northwest Ethiopia. Bahir Dar City is located 552 kilometers away from the capital city of Ethiopia (Addis Ababa). In the city, there are three governmental hospitals (two referral and one primary) and 10 governmental health centers, four private hospitals (one primary and three general), more than 22 private clinics, 28

Table I Different Brands of Furosemide $40 \mathrm{mg}$ Tablets Included in the Study

\begin{tabular}{|c|c|c|c|c|}
\hline $\begin{array}{l}\text { Brand } \\
\text { Code }\end{array}$ & $\begin{array}{l}\text { Brands } \\
\text { Name }\end{array}$ & $\begin{array}{l}\text { Batch/ } \\
\text { Lot No. }\end{array}$ & $\begin{array}{l}\text { Price/Strip (10 } \\
\text { Tab), ETB }\end{array}$ & $\begin{array}{l}\text { Country } \\
\text { of Origin }\end{array}$ \\
\hline $\mathrm{FI}$ & Lasix $^{\circledR}$ & $8 \mathrm{M} 66 \mathrm{C}$ & 110 & France \\
\hline F2 & $\begin{array}{l}\text { Furo } \\
\text { Denk }\end{array}$ & 985 & 40 & Germany \\
\hline F3 & Rasitol & $\mathrm{CH} 003$ & 12 & Malaysia \\
\hline $\mathrm{F} 4$ & Salurin & 0043 & 12 & Ethiopia \\
\hline F5 & Fusid & 26802 & 4 & Ethiopia \\
\hline
\end{tabular}

pharmaceutical wholesalers, 56 pharmacies and 50 drug stores. The reason for selecting this study area was due to the availability of a large number of community pharmacies, drug stores, wholesalers, and both private and governmental health organizations (hospitals and clinics). Most of the governmental and community pharmacies in Amhara region purchase pharmaceuticals from this city, thus many clients have access to both prescribed and non-prescribed (OTC) drugs.

\section{Sampling and Sample Size Determination}

Sampling design, sampling and sample size determination was adapted with some modifications from previous studies. ${ }^{22}$ Information was gathered on available brands of furosemide $40 \mathrm{mg}$ tablets from pharmacy professionals in community pharmacies of Bahir dar city, Northwest Ethiopia. A total of 5 brands of furosemide tablets were available in the market during the study period. Registered lists of 56 pharmacies and 50 drug stores were obtained from the Bahir Dar City health office. The list was then sorted alphabetically, numbered and coded. To avoid repetition of drugs to be sampled, $10 \mathrm{com}$ munity pharmacies of which 7 were pharmacies and 3 drug stores were randomly selected using a lottery method. Pharmacy personnel who were trained and acted as simulated caregivers visited each of the selected community pharmacies with a prescription for furosemide tablets. For each brand of furosemide tablets, a total of 120 tablets were purchased from the selected community pharmacies in Bahir dar city, Ethiopia. The experiment was undertaken at the quality control laboratory department of Human Well Pharmaceutical P.L.C. located in Amhara region, North Shoa, Ethiopia.

\section{In vitro Quality Control Test methods}

Different brands of furosemide $40 \mathrm{mg}$ tablets collected from the study area were tested for identification, uniformity of dosage units, friability, hardness, diameter, thickness, disintegration time, dissolution and assay according to procedures described in United States and British Pharmacopeia. ${ }^{4,23}$

\section{Identification Test}

High performance liquid chromatography (HPLC) was used to confirm the presence of the correct active pharmaceutical ingredient (API) in the pharmaceutical dosage form. The test was achieved by comparison of peak retention time of the sample and standard solution. ${ }^{23}$

\section{Weight Variation Test}

Twenty tablets from each brand were individually weighed as $\mathrm{X} 1, \mathrm{X} 2, \mathrm{X} 3 \ldots \mathrm{X}_{20}$ using an analytical balance and then 
the average weight, percentage deviation and standard deviation (SD) were determined. ${ }^{23}$

Average weight of 20 tablets was calculated using the formula:

$$
\text { mean }=\frac{(\mathrm{X} 1+\mathrm{X} 2+\mathrm{X} 3 \ldots+\mathrm{X} 20)}{20}
$$

Percentage deviation was calculated using the formula:

Percentage deviation of Weight Variation

$$
=\frac{\left(\begin{array}{c}
\text { Individual tablet } \\
\text { weight }
\end{array}-\begin{array}{c}
\text { Average weight of } \\
20 \text { tablets }
\end{array}\right)}{\begin{array}{c}
\text { Average weight } \\
\text { of } 20 \text { tablets }
\end{array}} \times 100
$$

\section{Hardness Test}

The hardness of tablets was determined using a hardness tester. Ten tablets were randomly taken from each brand and each tablet was then placed in the hardness tester. The tester was set to crush each tablet and the force required to crush each tablet was measured in newtons $(\mathrm{N})$. The average crushing force and SD were calculated. ${ }^{4}$

\section{Friability Test}

Twenty tablets were randomly taken from each brand then accurately weighed and placed on a sieve, and any loose dust was removed with the aid of a soft brush. Then the tablets were placed in the drum which was adjusted to rotate at $25 \mathrm{rpm}$ for $4 \mathrm{~min}$ and had a total of 100 revolutions. After completing the rotation, the drum was stopped and tablets were removed from it. The loose dust from the tablets was removed and the tablets were weighed. The percentage of friability for each brand was calculated using the formula: ${ }^{23}$

$$
=\frac{\left(\begin{array}{c}
\text { initial weight of } \\
20 \text { tablets }
\end{array}-\begin{array}{c}
\text { final weight of } \\
20 \text { tablets }
\end{array}\right)}{\begin{array}{c}
\text { initial weight of } \\
20 \text { tablets }
\end{array}} \times 100
$$

\section{Disintegration Time Test}

Six tablets from each brand of furosemide were randomly selected and each tablet was placed in one of six separate tubes, then the basket rack assembly was set to move up and down. The temperature of the medium ( $900 \mathrm{~mL}$ water) was maintained at $37 \pm 2{ }^{\circ} \mathrm{C}$. The disintegration time was taken to be the time when no particles remained in the basket. The time in minutes required for each tablet to disintegrate was recorded and average disintegration time for each product was calculated. ${ }^{23}$

\section{Dissolution Test}

The dissolution test was conducted according to the USP monograph on six tablets of each brand using a dissolution tester equipped with rotary paddles (USP Apparatus 2) operated at 50 revolutions per minute. The dissolution medium was $900 \mathrm{~mL}$ phosphate buffer ( $\mathrm{pH}$ 5.8) maintained at $37 \pm 0.5{ }^{\circ} \mathrm{C} .9 \mathrm{~mL}$ of sample solution was sampled at 10, 20,30, 45, and $60 \mathrm{~min}$ and equivalent amount of dissolution medium was immediately replaced. After filtration and appropriate dilution, the amount of drug dissolved was determined using a UV-visible spectrophotometer at the wavelength of $274 \mathrm{~nm}^{23}$

The amount of furosemide $\left(\mathrm{C}_{12} \mathrm{H}_{11} \mathrm{ClN}_{2} \mathrm{O}_{5} \mathrm{~S}\right)$ dissolved was determined using UV-visible spectrophotometry at $274 \mathrm{~nm}$ using a 1-cm quartz cell, and the medium as a blank.

Percentage amount of furosemide dissolved

$$
=\frac{\text { A sample }}{\text { A standard }} \times 100
$$

Where, $\mathrm{A}_{\text {sample }}=$ absorbance of the sample solution, $A_{\text {Standard }}=$ absorbance of the standard solution.

\section{Assay Test}

The assay test was conducted according to the specified monograph of USP. ${ }^{23}$

\section{Chromatography Conditions}

An HPLC system with a $4.6 \mathrm{~mm} \times 25 \mathrm{~cm}$ column, with a 5 - $\mu \mathrm{m}$ packing made up of $\mathrm{C}_{18}$, and a UV-vis detector adjusted at a wavelength of $254 \mathrm{~nm}$ was used and the column temperature was maintained at $30{ }^{\circ} \mathrm{C}$. The flow rate and injection volume used for assay were $1.0 \mathrm{~mL} / \mathrm{min}$ and $20 \mu \mathrm{L}$, respectively.

Mobile phase preparation: The mobile phase was prepared from a mixture of tetrahydrofuran: glacial acetic acid: water in a 30:1:70 ratio and the solution was filtered and degassed.

Standard solution preparation: $10 \mathrm{mg}$ of furosemide reference standard was accurately weighed and was transferred to a $10 \mathrm{~mL}$ volumetric flask. Then, $5 \mathrm{~mL}$ of a mixture of acetonitrile: water (50:50) and glacial acetic acid (978:22) solution was added and shaken for $5 \mathrm{~min}$, diluted with a mixture of acetonitrile: water (50:50) and glacial acetic acid (978:22) solution to volume, to obtain 
a solution having a known concentration of $1 \mathrm{mg} / \mathrm{mL}$ of furosemide.

Sample solution preparation: 20 tablets from each brand were weighed and powdered. An accurately weighed portion of the powder, $201.9 \mathrm{mg}$ (F1), $124.6 \mathrm{mg}$ (F2), $201.6 \mathrm{mg}$ (F3), $241.1 \mathrm{mg}$ (F4), and $247.4 \mathrm{mg}$ (F5), equivalent to $50 \mathrm{mg}$ of furosemide was transferred to a $50 \mathrm{~mL}$ volumetric flask; $30 \mathrm{~mL}$ of a mixture of acetonitrile: water (50:50) and glacial acetic acid (978:22) solution was added and sonicated for $10 \mathrm{~min}$. Then, a mixture of acetonitrile: water (50:50) and glacial acetic acid (978:22) solution was added to volume; mixed, filtered, and degassed to obtain a solution having a known concentration of about $1 \mathrm{mg} / \mathrm{mL}$ of furosemide.

Equal volumes $(20 \mu \mathrm{L})$ of the standard preparation and assay preparation were separately injected along with a blank solution into the HPLC system and the peak responses were recorded. The percentage content of furosemide $\left(\mathrm{C}_{12} \mathrm{H}_{11} \mathrm{ClN}_{2} \mathrm{O}_{5} \mathrm{~S}\right)$ in the portion of tablets was calculated using the following formula:

$\%$ content of the drug $=\left\{\frac{50 \times \mathrm{C} \times \mathrm{Ru}}{\mathrm{Rs}}\right\} \times \frac{1}{50} \times 100$

$\times$ Purity of furosemide standard

Where, $\mathrm{C}$ is the concentration, in $\mathrm{mg} / \mathrm{mL}$, of furosemide reference standard in the standard preparation, and $\mathrm{Ru}$ and $R s$ are the peak responses obtained from the assay preparation and the standard preparation, respectively.

System suitability test: System suitability was evaluated by performing five replicate injections of $1 \mathrm{mg} / \mathrm{mL}$ furosemide reference standard solution with the volume of $20 \mu \mathrm{L}$ into the HPLC system and calculating the percentage relative standard deviation (\% RSD) of their peaks.

\section{Data Quality Control}

Data were checked for completeness and consistency. Quality of experimental results was assured by performing system suitability tests and by strictly applying the procedures as described in the specified monographs of the pharmacopeia.

\section{Data Analysis}

Data obtained from the experiment were checked for completeness. Data were expressed in terms of mean $\pm \mathrm{SD}$. The dissolution profiles of the different brands of furosemide tablets were compared using one-way ANOVA. $P<0.05$ was considered as statistically significant. A model independent mathematical approach was also used to compare the dissolution profiles of the samples and the reference product using difference factor (f1) and similarity factor (f2).

\section{Results and Discussion}

Evaluating the quality of medicines circulating in the market is important to reduce the risk of having poor quality medicines in the supply chain. In this study, we assessed the pharmaceutical quality of commonly available brands of furosemide tablets in Northwest Ethiopia. Among five brands of furosemide tablets included in this study, three brands were imported from foreign countries while two were manufactured locally. Furthermore, all furosemide brands were subjected to a number of quality control tests in order to assess their dissolution profile along with other quality parameters including weight variation, friability, hardness, disintegration and assay.

\section{Identification Test}

In this study, the retention times of furosemide tablets ranged from $20.6 \mathrm{~min}(\mathrm{~F} 1)$ to $21.1 \mathrm{~min}(\mathrm{~F} 3)$ and the peak retention times of furosemide standard was 20.4 min as shown in Table 2 and Figures S1-S6. All samples analyzed displayed retention times corresponding with that of the respective standards. This confirmed the authenticity of the API(s) contained in the medicines.

\section{Weight Variation Test}

The minimum and maximum percentage deviation for each brand of furosemide tablet was -0.02 and -1.37 (F1), -0.07 and 2.87 (F2), -0.05 and 3.29 (F3), 0.15 and -4.50 (F4), and -0.07 and -3.99 (F5) respectively (Table 3 ). The weight variation limits for tablets differ depending on the average tablet weights. Since the mean weight of brand F2 was $98.9 \mathrm{mg}$, which is $<130 \mathrm{mg}$, the percentage deviation of each F2 tablet should be less than \pm 10 ; whereas the mean weights of brands F1, F3, F4 and F5 were $162.7 \mathrm{mg}$,

Table 2 Peak Retention Time of Furosemide Tablets

\begin{tabular}{|l|l|l|}
\hline Sample & $\begin{array}{l}\text { Peak Retention Time } \\
\text { (min) }\end{array}$ & $\begin{array}{l}\text { Identity } \\
\text { Test }\end{array}$ \\
\hline Furosemide reference & 20.4 & Pass \\
standard & & \\
FI & 20.6 & Pass \\
F2 & 20.7 & Pass \\
F3 & 21.1 & Pass \\
F4 & 20.8 & Pass \\
F5 & 20.7 & Pass \\
\hline
\end{tabular}

Abbreviations: FI, Lasix ${ }^{\circledR}$; F2, Furo Denk; F3, Rasitol, F4, Salurin, F5, Fusid. 
Table 3 Results of Weight Variation Test for Furosemide Tablets

\begin{tabular}{|c|c|c|c|c|c|c|c|c|c|c|}
\hline \multirow[t]{2}{*}{ No. of Tablets } & \multicolumn{5}{|c|}{ Individual Weight of Tablets (Iw) (mg) } & \multicolumn{5}{|c|}{$\%$ Deviation $=(I w-M) / M \times 100$} \\
\hline & FI & $\mathbf{F 2}$ & $\mathbf{F 3}$ & $\mathbf{F 4}$ & $\mathbf{F 5}$ & $\mathbf{F I}$ & $\mathbf{F 2}$ & $\mathbf{F 3}$ & F4 & $\mathbf{F 5}$ \\
\hline I & 162.70 & 99.70 & 159.40 & 198.30 & 202.50 & -0.02 & 0.84 & -1.29 & 1.33 & 2.00 \\
\hline 2 & 163.20 & 97.50 & 159.50 & 197.00 & 203.40 & 0.29 & -1.38 & -1.23 & 0.66 & 2.45 \\
\hline 3 & 162.40 & 98.70 & 160.90 & 196.30 & 195.70 & -0.20 & -0.17 & -0.36 & 0.31 & -1.43 \\
\hline 4 & 161.20 & 100.90 & 159.90 & 198.40 & 196.40 & -0.94 & 2.06 & -0.98 & 1.38 & -1.07 \\
\hline 5 & 163.50 & 99.10 & 159.90 & 201.10 & 197.30 & 0.47 & 0.24 & -0.98 & 2.76 & -0.62 \\
\hline 6 & 164.00 & 100.70 & 157.90 & 196.00 & 194.90 & 0.78 & 1.86 & -2.22 & 0.15 & -1.83 \\
\hline 7 & 164.20 & 98.60 & 159.70 & 192.60 & 199.50 & 0.90 & -0.27 & -1.11 & -1.58 & 0.49 \\
\hline 8 & 164.10 & 98.20 & 165.50 & 194.80 & 202.00 & 0.84 & -0.67 & 2.49 & -0.46 & 1.75 \\
\hline 9 & 162.90 & 98.10 & 166.80 & 194.90 & 198.40 & 0.10 & -0.77 & 3.29 & -0.41 & -0.07 \\
\hline 10 & 162.10 & 98.80 & 160.70 & 202.30 & 197.40 & -0.39 & -0.07 & -0.49 & 3.37 & -0.57 \\
\hline II & 163.90 & 99.00 & 162.30 & 186.90 & 199.60 & 0.72 & 0.14 & 0.50 & -4.50 & 0.54 \\
\hline 12 & 161.10 & 98.10 & 162.60 & 193.30 & 201.20 & -1.00 & -0.77 & 0.69 & -1.23 & 1.34 \\
\hline 13 & 160.50 & 99.60 & 163.10 & 196.90 & 201.60 & -1.37 & 0.74 & 1.00 & 0.61 & 1.55 \\
\hline 14 & 163.50 & 100.40 & 162.00 & 191.60 & 199.80 & 0.47 & 1.55 & 0.32 & -2.10 & 0.64 \\
\hline 15 & 162.10 & 98.00 & 159.20 & 190.10 & 204.70 & -0.39 & -0.87 & -1.41 & -2.86 & 3.11 \\
\hline 16 & 162.50 & 97.70 & 158.20 & 200.10 & 195.10 & -0.14 & -1.18 & -2.03 & 2.25 & -1.73 \\
\hline 17 & 161.60 & 101.70 & 163.80 & 194.30 & 196.50 & -0.69 & 2.87 & 1.43 & -0.72 & -1.02 \\
\hline 18 & 161.90 & 97.20 & 163.60 & 199.40 & 192.50 & $-0.5 \mathrm{I}$ & -1.68 & 1.31 & 1.89 & -3.04 \\
\hline 19 & 164.30 & 96.60 & 163.30 & 199.50 & 201.50 & 0.96 & -2.29 & 1.12 & 1.94 & 1.50 \\
\hline 20 & 162.90 & 98.70 & 161.40 & 190.20 & 190.60 & 0.10 & -0.17 & -0.05 & -2.81 & -3.99 \\
\hline Mean \pm SD & $162.7 \pm 1.12$ & $98.9 \pm 1.31$ & $161.5 \pm 2.39$ & $195.7 \pm$ & $4.06,198.5 \pm 3.72$ & & & & & \\
\hline
\end{tabular}

Abbreviations: M, mean weight of 20 tablets; SD, standard deviation; N, FI, Lasix ${ }^{\circledR}$; F2, Furo Denk; F3, Rasitol, F4, Salurin, F5, Fusid.

Table 4 Results of Friability, Hardness, Disintegration Time and Assay of Five Brands of Furosemide Tablets

\begin{tabular}{|l|l|l|l|l|}
\hline Brand Code & Mean Hardness (N) \pm SD & \% Friability & Disintegration Time (min) \pm SD & Assay(\%) \pm SD \\
\hline FI & $71.0 \pm 7.6$ & 0.37 & $1.14 \pm 0.09$ & $98.73 \pm 2.36$ \\
F2 & $55.8 \pm 10.2$ & 0.30 & $1.26 \pm 0.13$ & $96.42 \pm 0.12$ \\
F3 & $57.1 \pm 18.4$ & 0.55 & $2.59 \pm 0.48$ & $101.53 \pm 6.32$ \\
F4 & $48.5 \pm 1.9$ & 0.10 & $2.11 \pm 0.77$ & $90.20 \pm 0.04$ \\
F5 & $70.4 \pm 11.8$ & 0.28 & $2.59 \pm 0.47$ & $98.65 I \pm 0.03$ \\
\hline
\end{tabular}

Abbreviations: N, Newton; FI, Lasix ${ }^{\circledR}$; F2, Furo Denk; F3, Rasitol, F4, Salurin, F5, Fusid.

$161.5 \mathrm{mg}, 195.7 \mathrm{mg}$ and $198.5 \mathrm{mg}$ respectively, which is between 130-324 mg; hence the percentage deviation of each of those tablets should be less than \pm 7.5 . This might be due to manufacturers using varying proportions of excipients during manufacturing process. Tablets meet the specification if not more than two tablets are outside the percentage limit and if no tablets differ by more than twice the percentage limit. ${ }^{23}$ The weight variation test results revealed that all brands of furosemide tablets tested were within the specified limits. To check whether tablets contain the proper amount of drug, weight of tablet should be routinely measured. Hence, the weight variation test is a very important quality control parameter and it has a relationship with content uniformity of solid dosage forms. ${ }^{24}$ Weight variation gives a rough idea of content uniformity, but is not a confirmatory test. High variability of dose may cause toxicity or insufficient therapeutic drug level. ${ }^{25}$

\section{Hardness Test}

As shown in Table 4, the hardness of furosemide tablets was found to be in the range of $48.5 \mathrm{~N} \pm 1.9-71.0 \mathrm{~N} \pm 7.6$. A force of about $40 \mathrm{~N}$ is the minimum requirement for satisfactory tablet hardness. ${ }^{26}$ According to this result, all brands of furosemide tablets fulfilled the limits of hardness test. Hardness is used to ascertain the quality of a tablet; it is an important parameter since tablets must have sufficient ability to survive the handling forces during packaging, breakage under conditions of storage and 
transportation. If the hardness of a tablet exceeds a certain limit, it increases the disintegration time, which ultimately affects the bioavailability. ${ }^{7,25}$ It may be especially important to carefully monitor tablet hardness for drug products that possess real or potential bioavailability problems or are sensitive to altered dissolution-release profiles. Adequate tablet hardness is a necessary requisite for consumer acceptance. ${ }^{27}$ Hardness also influences friability and disintegration which means the less hard a tablet, the more friable it is and the less time it takes to disintegrate. $^{28}$

\section{Friability Test}

As shown in Table 4, the percentage friability of furosemide tablets were in the range of $0.10 \%(\mathrm{~F} 4)$ to $0.55 \%(\mathrm{~F} 3)$. According to $\mathrm{USP}^{23}$ the percentage friability should be less than $1 \%$. The percentage friability of all the brands of furosemide tablets was found to be less than $1 \%$, hence all the tested brands met the specification of friability. Therefore, furosemide tablets circulating in Northwest Ethiopia had good strength and can tolerate shocks during transportation and handling. Adequate tablet friability is a necessary requirement for consumer acceptance. ${ }^{8}$ High friability means that the drug is more likely to suffer mechanical erosion which may cause loss of the active ingredient and thus compromise its efficacy. ${ }^{29}$ As the hardness of a tablet increases, there is a marked decrease in the percentage of friability in all formulations. So the harder the tablet, the less will be the percentage friability and vice versa. ${ }^{27}$ The tendency of tablets to powder can affect the cosmetic appearance, consumer acceptance of the tablet and also add to a tablet's weight variation or content uniformity problems. ${ }^{24}$

\section{Disintegration Time Test}

The mean disintegration time results of furosemide tablets was between $1.14 \mathrm{~min}$ and $2.59 \mathrm{~min}$, as shown in Table 4 . Uncoated and film coated tablets should disintegrate within 30 min. $^{23}$ Hence, all the brands of furosemide tablets were within the acceptable limits. Disintegration is the breakdown process of a tablet into smaller particles and is the first step towards dissolution. ${ }^{29,30}$ A drug can have a rapid disintegration time but this does not mean the drug is biologically available. $^{31}$ If the disintegration time is too high; it means that the tablet is too highly compressed and if the disintegration time is not uniform, it indicates batch inconsistency and lack of batch uniformity.

\section{Dissolution Test}

As shown in Table 5, the mean percentage of furosemide API released was found in the range of $80.7 \pm 0.63(\mathrm{~F} 4)$ to 82.9 \pm 1.0 (F3) at $60 \mathrm{~min}$. According to $\mathrm{USP}^{23}$ the percentage amount of furosemide dissolved within $60 \mathrm{~min}$ should not be less than $80 \%(\mathrm{Q})$. The dissolution test results revealed that all the brands met USP dissolution limits. Dissolution is considered an important tool to predict in vivo bioavailability and has been used to prove bioequivalence to allow interchangeability. Very often FDA considers dissolution testing to be more discriminating than an in vivo test. Difference factor(f1) and similarity factor(f2) have been used frequently for in vitro bioequivalence studies by comparing the dissolution profiles of different brands of pharmaceutical dosage forms with the innovator product. ${ }^{32,33}$ Dissolution testing and consequently comparing the dissolution profiles can be used to establish similarity of the generic brands to the original product. This test is employed to distinguish the effect of manufacturing variables, including the binder type, excipient type, mixing process, and granulation procedure. Therefore, it is a relatively rapid and inexpensive technique to predict the in-vivo performance of pharmaceutical dosage forms. ${ }^{34}$ Hence, it will promote interchangeability of the products, will ensure the same pharmacological effect and the lower cost will be a benefit to the patient.

\section{Dissolution Profile Comparison}

A model independent approach was used to compare the dissolution profiles of the samples and the reference product

Table 5 Percentage of Furosemide API Released at Different Sampling Times $(n=6)$

\begin{tabular}{|l|l|l|l|l|l|}
\hline Sampling Time Points (min) & FI & F2 & F3 & F4 & F5 \\
\hline 10 & $68.7 \pm 0.4$ & $67.7 \pm 2.9$ & $59.7 \pm 6.9$ & $66.9 \pm 1.2$ & $59.0 \pm 5.6$ \\
20 & $73.2 \pm 0.3$ & $68.7 \pm 0.9$ & $65.1 \pm 6.8$ & $72.2 \pm 1.3$ & $59.9 \pm 8.3$ \\
30 & $74.2 \pm 0.2$ & $71.6 \pm 0.7$ & $73.0 \pm 2.5$ & $73.0 \pm 0.5$ & $74.1 \pm 1.1$ \\
45 & $79.5 \pm 0.1$ & $80.2 \pm 1.4$ & $78.1 \pm 2.0$ & $77.6 \pm 1.5$ & $77.1 \pm 2.0$ \\
60 & $82.2 \pm 0.40$ & $81.2 \pm 0.48$ & $82.9 \pm 1.00$ & $80.7 \pm 0.63$ & $82.2 \pm 0.72$ \\
\hline
\end{tabular}

Abbreviations: FI, Lasix ${ }^{\circledR}$; F2, Furo Denk; F3, Rasitol, F4, Salurin, F5, Fusid. 
Table 6 Difference Factor ( $\mathrm{fl}$ ) and Similarity Factor (f2) of Furosemide Brands

\begin{tabular}{|l|l|l|}
\hline Brands & fI & f2 \\
\hline FI & - & - \\
F2 & 2.6 & 82.7 \\
F3 & 5.4 & 64.5 \\
F4 & 2.0 & 88.2 \\
F5 & 6.8 & 58.1 \\
\hline
\end{tabular}

using difference factor (f1) and similarity factor (f2). To assess in vitro bioequivalence, mean dissolution values were employed to estimate $\mathrm{fl}$ and $\mathrm{f} 2$. The following equations were used to calculate $\mathrm{fl}$ and $\mathrm{f} 2$ for the studied tablets. ${ }^{35}$

$$
\begin{gathered}
\mathrm{f} 1=\left\{\frac{\sum_{t=1}^{n}|R t-T t|}{\sum_{t=1}^{n} R t}\right\} \times 100 \\
\mathrm{f} 2=50 \log \left\{\left[1+\left(\frac{1}{\mathrm{n}}\right) \sum_{\mathrm{t}=1}^{\mathrm{n}}(\mathrm{Rt}-\mathrm{Tt})^{2}\right]^{-0.5} 100\right\}
\end{gathered}
$$

Where $\mathrm{n}$ is the number of time points, $R t$ is the dissolution value of the reference product at time $t$, and $T t$ is the dissolution value of the test product at time $t$.

In this study, difference factor (f1) values were less than 15 and similarity factor (f2) values were greater than 50 for the brands of furosemide tablets (Table 6). This indicates that release of the drug from all the furosemide tablets is similar to the innovator product. As shown in Figure 1, the dissolution profile of the different brands of furosemide tablets and comparator product indicated that there is a similar behavior of dissolution profile curves. Two dissolution profiles are considered similar and bioequivalent, if $\mathrm{fl}$ is between 0 and 15 and $\mathrm{f} 2$ is between 50 and $100 .{ }^{35}$ Hence based on this requirement, all the brands of furosemide tablets could be used interchangeably with a comparator drug in clinical practice. Similarly, one-way analysis of variance (ANOVA) at 95\% CI showed that the dissolution profiles of the furosemide tablets were not significantly different from their innovator product at $60 \mathrm{~min}$.

\section{Amount of Active Pharmaceutical Ingredient} System Suitability Test

According to USP, ${ }^{23}$ an HPLC system is suitable, if percent relative standard deviation (\% RSD) calculated from the peak area obtained from five replicate injections is not more than $2 \%$. The system suitability test results of peak area responses \% RSD was $0.19 \%$. Hence, the system was suitable (Table 7).

Furosemide tablets are specified to contain $90-105 \%$ of the label claim. ${ }^{35}$ The assay results of furosemide tablets ranged from $90.2 \%(\mathrm{~F} 4)$ to $101.53 \%(\mathrm{~F} 3)$ as shown in Table 4. Hence, all of the samples passed the assay test. Assay of pharmaceutical products is a critical quality parameter required to confirm that the labeled amount of drug is available in a given dosage form and failure to meet the standard will result in poor quality medicines. ${ }^{36}$ Inadequate amounts of API will result in under-dosed

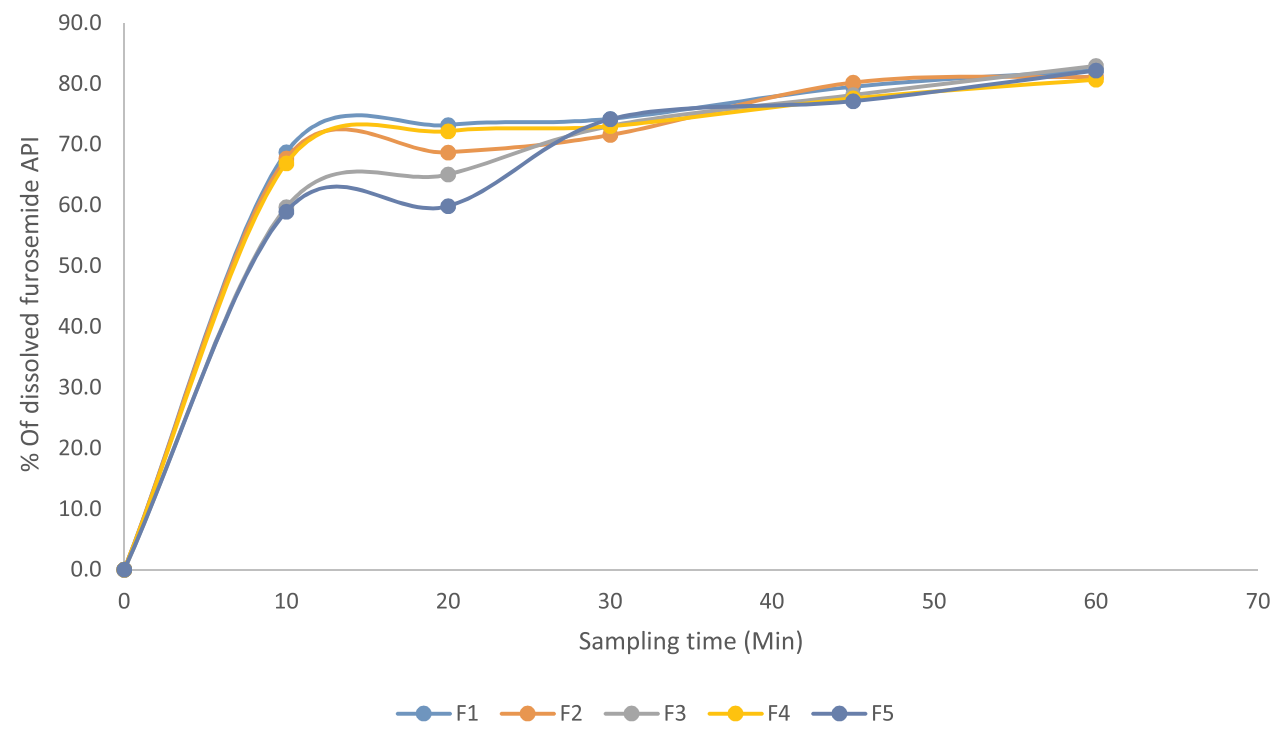

Figure I Dissolution profiles for different brands of furosemide tablets. 
Table 7 System Suitability Test Results for Chromatographic Assay of Furosemide Tablets

\begin{tabular}{|l|l|l|l|}
\hline Injections & $\begin{array}{l}\text { Peak Area } \\
\text { (mAU*min) }\end{array}$ & $\begin{array}{l}\text { Tailing } \\
\text { Factor }\end{array}$ & $\begin{array}{l}\text { Theoretical } \\
\text { Plates }\end{array}$ \\
\hline 1 & 413.8036 & 1.04 & 9868 \\
2 & 413.9134 & 1.03 & 9946 \\
3 & 413.6563 & 1.03 & 10,018 \\
4 & 415.5401 & 1.03 & 10,761 \\
5 & 413.9459 & 1.02 & 10,273 \\
Mean & 414.1719 & 1.03 & 10,173 \\
$\%$ RSD & $0.19 \%$ & $0.76 \%$ & $3.56 \%$ \\
\hline
\end{tabular}

medication, leading to poor treatment outcomes while excessive amounts of API cause over-dosage of medication, leading to increased adverse drug reactions and treatment failure.

\section{Conclusion}

This study attempted to assess the quality as well as the physicochemical bioequivalence of different brands of furosemide tablets. In this study, all the tested brands of furosemide tablets passed minimum standards for major quality attributes and were considered to be of good quality. Difference factor (f1) and similarity factor (f2) values of all the tested brands of furosemide tablets indicated that the release of the drug from all samples analyzed is similar to the innovator product. Hence, all these generic brands of furosemide tablets could be used interchangeably in clinical practice.

\section{Data Sharing Statement}

Data can be obtained from the corresponding author on reasonable request.

\section{Acknowledgment}

The authors are very grateful to Human Well Pharmaceutical Ethiopia factory for providing laboratory facilities for this research work. They are also grateful to the Ethiopian Food and Drug Authority (EFDA) for donating the standard. Finally, they would like to acknowledge Wollo University for sponsoring this study.

\section{Disclosure}

The authors declare that they have no competing interests in this work.

\section{References}

1. Abula T, Rao SA, Mengistu A For Health Science Students. 2004.

2. Mohamed M, Siaan KAA, Almarzouki A, Anwair MA. Evaluation of the pharmaceutical quality of some furosemide tablet brands. Int J Pharm Chem Sci. 2015;4(2):238-246.

3. Katzung BG. Basic and Clinical Pharmacology. Mc Graw Hill; 2012.

4. Pharmacopeia B. Vols. 1-4. London: The Stationary Office;2009:2009-10952.

5. Sultana S, Hosen MS. In vitro comparative quality evaluation of different brands of esomeprazole tablets available in selected community pharmacies in Dhaka, Bangladesh. BMC Res Notes. 2018;11 (1):184. doi:10.1186/s13104-018-3285-x

6. Uddin MS, Al Mamun A, Hossain MS, et al. In vitro quality evaluation of leading brands of ciprofloxacin tablets available in Bangladesh. BMC Res Notes. 2017;10(1):185. doi:10.1186/s13104017-2507-y

7. Solomon Hambisa SB, Suleman S. In vitro comparative quality assessment of different brands of norfloxacin tablets available in Jimma, Southwest Ethiopia. Drug Des Devel Ther. 2019;13:1241. doi:10.2147/DDDT.S189524

8. Dires T. A Comparative in-vitro Evaluation of Anti-Hypertensive Drugs Products (Methyldopa, Furosemide and Propranolol Tablets) from Local Market. Addis Ababa: Addis Ababa University; 2005.

9. Kitutu FE Screening Drug Quality Project. 2015.

10. Nsimba SE Problems associated with substandard and counterfeit drugs in developing countries: a review article on global implications of counterfeit drugs in the era of anti-retroviral (ARVS) drugs in a free market economy. 2009.

11. Frimpong G, Ofori-Kwakye K, Kuntworbe N, et al. Quality assessment of some essential children's medicines sold in licensed outlets in Ashanti Region, Ghana. J Trop Med. 2018;2018.

12. Petersen A, Held N, Heide L, Group D-EMS. Surveillance for falsified and substandard medicines in Africa and Asia by local organizations using the low-cost GPHF Minilab. PLoS One. 2017;12(9): e0184165. doi:10.1371/journal.pone.0184165

13. Suleman S. Comparative in-vitro Quality Evaluation of Tablets of the Commonly Prescribed Antiepileptic Drugs, Carbamazepine and Phenobarbital, from Drug Retail Outlets in Addis Ababa. Addis Ababa University; 2005.

14. Oli AN, Ibeabuchi MU, Enweani IB, Emencheta SC. Pharmaceutical quality of selected metronidazole and ciprofloxacin infusions marketed in South Eastern Nigeria. Drug Healthc Patient Saf. 2020;12:103. doi:10.2147/DHPS.S246050

15. Macquart de Terline D, Diop BI, Bernard M, et al. Substandard drugs among five common antihypertensive generic medications: an analysis from 10 African countries. J Hypertens. 2018;36(2):395-401. doi:10.1097/HJH.0000000000001560

16. Ndichu ET, Ohiri K, Sekoni O, Makinde O, Schulman K. Evaluating the quality of antihypertensive drugs in Lagos State, Nigeria. PLoS One. 2019;14(2):e0211567. doi:10.1371/journal. pone. 0211567

17. Suleman S, Zeleke G, Deti H, et al. Quality of medicines commonly used in the treatment of soil transmitted helminths and giardia in Ethiopia: a nationwide survey. PLoS Negl Trop Dis. 2014;8(12): e3345. doi:10.1371/journal.pntd.0003345

18. Abuye H, Abraham W, Kebede S, Tatiparthi R, Suleman S. Physicochemical quality assessment of antimalarial medicines: chloroquine phosphate and quinine sulfate tablets from drug retail outlets of South-West Ethiopia. Infect Drug Resist. 2020;13:691. doi:10.2147/IDR.S234684

19. Seifu A, Kebede E, Bacha B, Melaku A, Setegn T. Quality of albendazole tablets legally circulating in the pharmaceutical market of Addis Ababa, Ethiopia: physicochemical evaluation. BMC Pharmacol Toxicol. 2019;20(1):20. doi:10.1186/s40360-019-0299-5 
20. Abou-Taleb BA, Megallaa MH, Khalafallah NM, Khalil SH. In-vitro and in-vivo performance of locally manufactured glimepiride tablet generics compared to the innovator (Amaryl ${ }^{\mathbb{B}}$ ) tablets. Drug Dev Ind Pharm. 2020;46(2):192-199. doi:10.1080/03639045.2020.1716369

21. Alemayehu C, Mitchell G, Nikles J, Aseffa A, Clavarino A. Acceptability and barriers to implementation of N-of-1 tests in Ethiopia-a qualitative study. BMC Med Res Methodol. 2019;19 (1):192. doi:10.1186/s12874-019-0832-7

22. Ebenezer CJ. Pharmaceutical Quality and Policy in Nigeria: Stakeholder Perspectives and Validation of the Mobile Authentication Service. UCL (University College London); 2015.

23. USP. United States Pharmacopeia. United States Pharmacopeial; 2015.

24. Tuli BM. Evaluation of Pharmaceutical Equivalence of Two Different Brands (Limaryl and Dactus) of Glimepiride Tablets (2mg) Available in Bangladesh. East West University; 2014.

25. Morshed N. Comparative Evaluation of Prednisolone 5MG Tablets Marketed in Bangladesh. 2015.

26. Kassahun H, Asres K, Ashenef A. In vitro and in vivo quality evaluation of glibenclamide tablets marketed in Addis Ababa, Ethiopia. J Pharmaceutics. 2018;2018.

27. Mosharraf Z. Determination of the Quality Control Parameters of Paracetamol Tablets in Bangladesh Pharma Market. 2012.

28. Baig A, Quraishi AR, e Zahir F. Post-market in-vitro comparative evaluation of quality control parameters of paracetamol compressed tablets manufactured in local industrial zones of Kpk Pakistan. The Pharma Innovation. 2013;2(3,Part A):11.
29. Allen L, Ansel HC. Ansel's Pharmaceutical Dosage Forms and Drug Delivery Systems. Lippincott Williams \& Wilkins; 2013.

30. Teklu L, Adugna E, Ashenef A. Quality evaluation of paracetamol tablets obtained from the common shops (kiosks) in Addis Ababa, Ethiopia. Int $j$ Pharm Sci Res. 2014;5(8):3502.

31. Lariba L Pharmaceutical equivalence studies on some locally manufactured brands of paracetamol sold in Kumasi 2017.

32. Al-Tabakha MM, Fahelelbom K, Obaid DEE, Sayed S. Quality attributes and in vitro bioequivalence of different brands of amoxicillin trihydrate tablets. Pharmaceutics. 2017;9(2):18. doi:10.3390/ pharmaceutics 9020018

33. Medina JR, Salazar DK, Hurtado M, Cortes AR, DomínguezRamírez AM. Comparative in vitro dissolution study of carbamazepine immediate-release products using the USP paddles method and the flow-through cell system. Saudi Pharm J. 2014;22(2):141-147. doi:10.1016/j.jsps.2013.02.001

34. Mubtasim N Analytical method development and validation of a combination formulation. 2015.

35. Begum R, Sultan MZ, Chowdhury JA, Amran MS. In vitro pharmaceutical equivalence study of three brands of atenolol tablets available in Bangladesh. Dhaka Univ J Pharm Sci. 2019;18(1):43-48. doi:10.3329/dujps.v18i1.41426

36. Gupta M. Quality Control Testing of Different Brands of Conventional Tablets of Ibuprofen Available in Trinidad \& Tobago, West Indies: An in-vitro Testing. Faculty of Medical Sciences, Research Day; 2019.

\section{Publish your work in this journal}

Drug Design, Development and Therapy is an international, peerreviewed open-access journal that spans the spectrum of drug design and development through to clinical applications. Clinical outcomes, patient safety, and programs for the development and effective, safe, and sustained use of medicines are a feature of the journal, which has also been accepted for indexing on PubMed Central. The manuscript management system is completely online and includes a very quick and fair peer-review system, which is all easy to use. Visit http://www. dovepress.com/testimonials.php to read real quotes from published authors. 